\title{
Penelitian Dasar Tentang Nilai Kekuatan Tekan dan Serapan Air dari Variasi Paving Blok Subtitusi Cangkang Sawit
}

\author{
A Preliminary Study on Compressive Strength and Water Absorption from Paving Block \\ Variations of Palm Shell Substitution
}

\author{
Muhammad Yamin ${ }^{* 1}$, Hartono Sitompul ${ }^{2}$, Mujibu Rahman ${ }^{1}$, Elisa ginsel popang ${ }^{1}$, Rudito ${ }^{1}$, \\ Ahmad Zamroni ${ }^{1}$, Anis Syauqi ${ }^{1}$, Jamaluddin ${ }^{1}$ \\ ${ }^{1} J u r u s a n$ Teknologi Pertanian, Politeknik Pertanian Negeri Samarinda, Indonesia. \\ ${ }^{2}$ PT. Maju Kalimantan Hadapan, Kalimantan Timur, Indonesia. \\ *Corresponding Author: yaminpoliagro@gmail.com
}

\begin{abstract}
Abstrak
Cangkang sawit adalah limbah hasil sampingan dari produk industry sawit, merupakan limbah yang terus ada dan berpotensi untuk terjadinya degredasi pada lingkungan secara umum, walau secara terbatas limbah ini masih digunakan untuk bahan bakar boiler di pabrik sawit. Namun potensinya yang sangat besar dirasa perlu untuk dimanfaatkan untuk produk lain yang punya nilai kemanfaatan yang lebih luas, yakni sebagai bahan subtitusi untuk pembuatan paving blok. Perancangan paving blok yang standar menjadi pilihan untuk penelitian dasar ini, yakni dengan ukuran $20 \times 20 \times 6 \mathrm{~cm}$, dengan metoda subtitusi menggunakan rasio berdasarkan volume isi. Adapun perbandingannya semen (S), Cangkang sawit (CS) dan Pasir (P), yakni dengan 3 perlakuan variasi yakni $1(\mathrm{~S}): 1.5(\mathrm{CS}): 4.5(\mathrm{P})$ (perlakuan 1); $1(\mathrm{~S}): 3(\mathrm{CS})$ : 3(P) (perlakuan 2) ; 1(S) : 4.5(CS): $1.5(\mathrm{P})$ (perlakuan 3). Pengujian paving blok dilakukan setelah proses pendinginan selama 28 hari, untuk mendapatkan nilai yang refresentatif. Hasil akhir penelitian dasar menunjukkan bahwa yang sesuai untuk standar penggunaan secara umum yakni pada perlakuan 1 dan 2 terutama dalam nilai tekan, sedangkan perlakuan 3 belum memenuhi standar yang diharapkan, yakni kesesuaian untuk masuk dalam standar SNI Paving Block SNI 03-0691-1996, dengan klasifikasi D, yakni penggunaan paving blok untuk Taman dan penggunaan semacamnya.
\end{abstract}

Kata Kunci: Kekuatan Tekan, Serapan Air, Paving Blok Subtitusi, Cangkang Sawit

\begin{abstract}
Palm kernel shells are waste byproducts of oil palm industrial s, they are waste that continues to exist and has the potential for degredation in the environment in generally, although this waste is still limited to fuel for boilers in palm oil mills. However, its huge potential is necessary to be used for other products that have a wider useful value, namely as a substitute material for making paving blocks. The standard paving block design is the choice for this basic research, namely the size of $20 \times 20 \times 6 \mathrm{~cm}$, with the substitution method using a ratio based on the volume of contents. The comparison is cement (S), palm kernel shell (CS) and sand $(P)$, namely with 3 treatment variations, namely $1(S): 1.5(C S): 4.5(P)$ (treatment 1); 1 (S): 3 (CS): $3(P)$ (treatment 2); $1(S): 4.5(C S): 1.5(P)$ (treatment 3). The paving block test is carried out after 28 days of cooling to get a representative value. The final results of the basic research show that what is appropriate for the use standards in general, namely treatment 1 and 2, especially in the compressive value, while treatment 3 does not meet the expected standard, namely the suitability for entry into the SNI Paving Block SNI 030691-1996 standard, classification D, namely the use of paving blocks for parks and similar uses.
\end{abstract}

Keywords: Compressive strenght, water absorbtion, Paving block, Palm Shell

\section{PENDAHULUAN}

Paving Block merupakan salah satu produk bangunan yang banyak digunakan oleh masyarakat karena kepraktisan dalam penggunaannya. Banyak digunakan untuk perkerasan permukaan jalan, lahan parkir kendaraan ataupun juga untuk dekoratif taman dan semacamnya. Paving blok merupakan bentukan dari mortar ataupun beton, yang mana umumnya mortar adalah campuran dari semen, pasir dan air yang dapat merekat dalam campuran beton. Umumnya mortar merupakan plasteran dalam pemasangan batu untuk melekatkan bata menjadi satu kesatuan yang kuat (Samiaji, 2010) 
Menurut Adriati (2013), keberadaan paving block bisa menggantikan aspal dan plat beton dengan banyak keuntungan yang dimilikinya. Beberapa kegunaan paving block diantaranya adalah : dapat diperoleh secara massal, mudah diaplikasikan tanpa perlu keahlian khusus, mudah dihamparkan tanpa menunggu pengerasan seperti beton, adanya por-pori pada paving block yang membuat infiltrasi air ke tanah bisa terjadi serta meminimalisasi aliran permukaan, nilai estetika yang lebih menarik serta harga yang lebih murah.

Banyak hal yang bisa menentuka kualitas paving block diantaranya adalah bahan dasar, bahan tambahan, proses pembuatan serta alat yang digunakan. Sehingga komposisi perbandingan campuran yang direncanakan dengan baik, proses percetakaannya yang sesuai akan menghasilkan paving block yang berkualitas dan memenuhi standar (Deden, 2004)

Banyaknya pabrik sawit yang bertebaran di Kalimantan Timur, adalah pertanda cukup melimpahnya limbah yang dihasilkan dan salah satunya adalah limbah cangkang. Sampai saat ini limbah sekam belum termanfaatkan secara optimal. Limbah tersebut biasanya menumpuk di sekitar penggilingan padi dan membusuk atau biasanya juga dibakar yang bisa menyebabkan polusi udara. Dari data yang ada saja bahwa potensi limbah cangkang yang ditulis oleh Sipayung (2012), menurutnya sekitar 40 ton per jam atau sekitar 800 ton sehari, yang mana $50 \%$ digunakan untuk bahan bakar boiler, sisanya adalah dibakar atau untuk pengerasan jalan.

Olehnya dengan melihat dampak dan potensi limbah cangkang sawit yang melimpah, maka alternatif untuk pemanfaatan limbah tersebut menjadi sangat perlu agar sehingga minimal menjadi masukan untuk membantu penyediaan alternative bahan baku untuk pembuatan paving Block secara umum.

\section{METODE PENELITIAN}

Penelitian ini berlangsung di laboratorium Rekayasa Pengolahan Kayu untuk proses pembuatan produk paving block sedangkan untuk proses pengujian dilakukan di Laboatorium Analisis Produk, Program Studi Teknologi Hasil Perkebunan, serta Laboratorium Sipil, Jurusan Teknik Sipil Universitas Mulawarman.

Penelitian ini menggunakan cangkang sawit sebagai bahan subtitusi untuk pembuatan paving block yang di kombinasikan dengan pasir dan semen, adapun rasio perbandingannya adalah sebagi berikut :

Tabel 1. Rasio Perbandingan Perlakuan Paving Block Subtitusi Cangkang Sawit

\begin{tabular}{cccc}
\hline \multirow{2}{*}{ Perlakuan } & \multicolumn{3}{c}{ Rasio Perbandingan } \\
\cline { 2 - 4 } & Semen & $\begin{array}{c}\text { Cangkang } \\
\text { Sawit }\end{array}$ & Pasir \\
\hline P1 & 1 & 1,5 & 4,5 \\
P2 & 1 & 3 & 3 \\
P3 & 1 & 4,5 & 1,5 \\
\hline
\end{tabular}

Pengujian dilakukan dengan tiga kali ulangan dan dikondisikan selama 28 hari. Adapun rujukan standar penilaian adalah menggunakan standar SNI 03-06911996.Batasan pengamatan pada penelitian dasar ini adalah uji kuat tekan dan daya serap air yang dimilki oleh setiap produk.

Tabel 2. Standar Nasional Indonesia (SNI 03-0691-1996)

\begin{tabular}{|c|c|c|c|c|}
\hline \multirow{2}{*}{ Mutu } & \multicolumn{2}{|c|}{ Kuat Tekan $\left(\mathrm{kg} / \mathrm{cm}^{2}\right)$} & \multirow{2}{*}{$\begin{array}{c}\begin{array}{c}\text { Penyerapan } \\
\text { Air }\end{array} \\
\text { Rata-Rata } \\
\text { Maks (\%) }\end{array}$} & \multirow{2}{*}{ Klasifikasi penggunaan } \\
\hline & Rata-Rata & Min & & \\
\hline A & 400 & 350 & 3 & Jalan \\
\hline B & 200 & 170 & 6 & Peralatan parkir \\
\hline C & 150 & 125 & 8 & Pejalan kaki \\
\hline $\mathrm{D}$ & 100 & 85 & 9 & Taman dan penggunaan lair \\
\hline
\end{tabular}




\section{HASIL PENELITIAN}

\section{A. Nilai Kuat Tekan}

Kuat tekan beton adalah besarnya beban per satuan luas, yang menyebabkan benda uji hancur bila dibebani dengan gaya tekan tertentu, yang dihasilkan oleh mesin pembebanan.Kuat tekan beton ditentukan oleh pengaturan dari perbandingan semen, agregat halus, agregat kasar, air, dan berbagai jenis campuran. Perbandingan air terhadap semen merupakan faktor utama dalam penentuan kuat tekan beton.(. Wariyatno dan .Haryanto, 2013).

Adapun nilai kuat tekan yang nampak dari hasil pengujian adalah, sebagaimana Tabel 3 berikut di bawah ini :

Tabel 3. Nilai Kuat Tekan dari Variasi Subtitusi Cangkang Sawit Pada Pembuatan Paving Block

\begin{tabular}{|c|c|c|c|c|}
\hline \multirow{2}{*}{ Perlakuan } & \multicolumn{3}{|c|}{ Ulangan } & \multirow{2}{*}{$\sum_{\left(\mathrm{kg} / \mathrm{cm}^{2}\right)} \mathrm{P}$} \\
\hline & U1 & U2 & U3 & \\
\hline P1 & 122,70 & 118,57 & 126,57 & 122,61 \\
\hline P2 & 88,21 & 96,42 & 88,21 & 90,94 \\
\hline P3 & 46,16 & 47,19 & 46,98 & 46,78 \\
\hline
\end{tabular}

Dari nilai yang nampak di atas, adalah menunjukkan adanya daya tekan yang menurun seiring pertambahan kuantitas cangkang sawit yang disubtitusikan ke dalam paving block. Sebagaimana yang dilihat jika ditransformasikan dalam bentuk gambar grafik sebagaimana pada Gambar 1 di bawah ini:

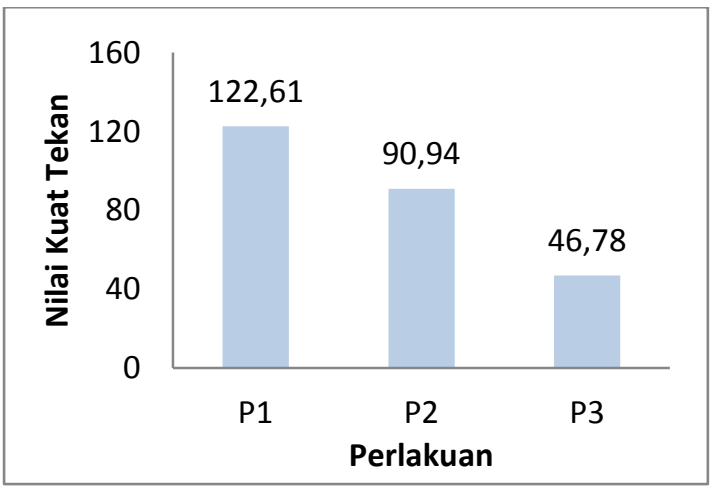

Gambar 1. Grafik Nilai Kuat Tekan $\left(\mathrm{Kg} / \mathrm{Cm}^{2}\right)$ Paving Block Subtitusi Cangkang Sawit Berdasarkan 3 Perlakuan (P1. P2 dan P3)

Nilai kuat tekan ternyata yang menindikasikan, bahwa semakin bertambah subtitusi cangkng sawit maka semakin kecil nilai kuat tekannya, begitu juga sebaliknya. Hal ini bisa disebabkan oleh kurangnya daya ikat antara cangkang sawit dan mortar mengakibatkan timbulnya pori-pori yang bisa terisi oleh udara. Hal ini tentu berakibat pada nilai kerapatan yang rendah. Nilai kerapatan rendah adalah salah satu penyebab dari besarnya nilai kaut tekan sebuah paving block.

Kandungan unsur kima cangkang sawit bisa juga memilki pengaruh terhadap kualitas kuat tekan paving block, apakah mendukung dalam hal peningkatan daya kita atau malah sebaliknya, hipotesa ini ternyata diperkuat oleh deden (2010), yang mengatakan bahwa hal yang memberikan perbedaan dalam penurunan kuat tekan paving block adalah kandungan senyawa lemak yang terdapat pada cangkang sawit, dan adanya kemungkinan perbedaan unsur kimia semen dan unsur kimia cangkang sawit dalam percampurannya. Maka semakin banyak kandungan senyawa yang menghambat pengikatan berakibat pada penurunan daya kuat tekan dari produk paving block yang diproduksi.

Dari hasil penelitian ternyata tidak semua masuk dalam kategori standar yang ditetapkan, namun ada yang tidak masuk standar yakni pada perlakuan ke 3 dengan rasio perbandingan adalah $1(\mathrm{~S}): 4.5(\mathrm{CS}): 1.5$ $(\mathrm{P})$, dan lainnya yakni perlakuan 1 dan 2 , masuk dalam kategori D, yakni untuk peruntukan taman dan semacamnya sesuai dengan standar SNI Paving Block 03-06911996. 
Tabel 4. Klasifikasi Paving Blok Cangkang Sawit Berdasarkan SNI 01-069-1996

\begin{tabular}{clcc}
\hline Kode & \multicolumn{1}{c}{ Komposisi } & $\sum \mathbf{P}\left(\mathbf{k g} / \mathbf{c m}^{\mathbf{2}}\right)$ & Kategori Mutu \\
\hline P1 & $1(\mathrm{~S}): 1.5(\mathrm{CS}): 4.5(\mathrm{P})$ & 122,61 & $\mathrm{D}$ \\
P2 & $1(\mathrm{~S}): 3(\mathrm{CS}): 3(\mathrm{P})$ & 90,94 & $\mathrm{D}$ \\
P3 & $1(\mathrm{~S}): 4.5(\mathrm{CS}): 1.5(\mathrm{P})$ & 46,78 & Tidak masuk kategori \\
\hline
\end{tabular}

Dari nilai yang terdapat pada Tabel 4 di atas menunjukkan bahwa PI dan P2 nilainya masuk pada kategori $D$, yang dalam standar SNI dikategorikan untuk skala aplikasi taman dan semacamnya, sebagaimana pada SNI 01-069-1996.

\section{B. Nilai Penyerapan Air}

Nilai penyerapan air adalah jumlah air yang terserap oleh paving block ketika dilakukan perendaman. Hal ini akan berhubungan dengan besarnya pori yang mempengaruhi kekuatan dari produk paving block. Adapun nilai yang diperoleh pada penelitian adalah disajikan pada Tabel 5 di bawah ini :

Tabel 5 . Nilai Penyerapan Air dari Variasi Subtitusi Cangkang Sawit pada Pembuatan Paving Block

\begin{tabular}{|c|c|c|c|c|}
\hline \multirow{2}{*}{ Perlakuan } & \multicolumn{3}{|c|}{ Ulangan } & \multirow{2}{*}{$\underset{(\%)}{\sum_{(\%)} P}$} \\
\hline & $\mathrm{U} 1$ & U2 & U3 & \\
\hline P1 & 4,49 & 4,48 & 5,57 & 4,85 \\
\hline P2 & 6,86 & 5,97 & 7,61 & 6,81 \\
\hline P3 & 8,28 & 8,79 & 9,43 & 8,83 \\
\hline
\end{tabular}

Dari hasil penelitian ternyata $\mathrm{P} 1, \mathrm{P} 2$ dan P3 masuk dalam kategori standar SNI Paving Block 03-0691-1996.

Dari data Gambar 2, nampak bahwa kenaikan nilai penyerapan air, sejalan dengan semakin meningkatnya subtitusi cangkang sawit. Biasanya daya serap air itu tergantung banyaknya pori yang bisa diisi oleh air. Ada kemungkinan sebagaimana penjelasan pada daya kuat tekan di atas, rendahnya daya ikat semen dengan cangkang sawit, inilah yang membuat banyaknya ruang kosong pada produk paving block. (Mustaqim, 2011).

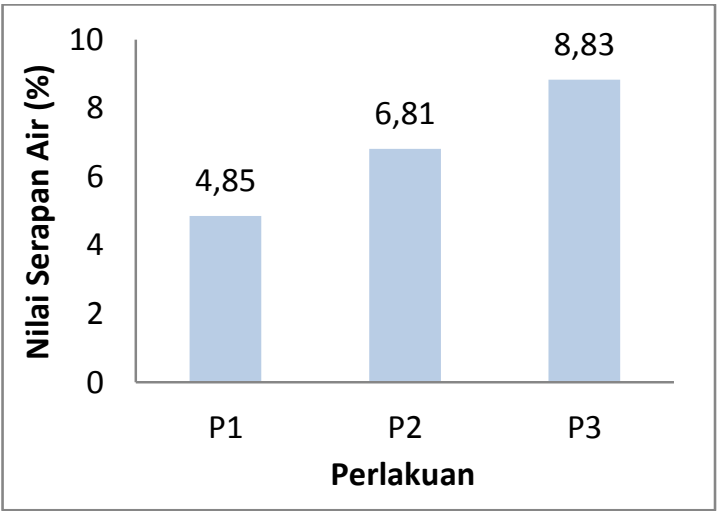

Gambar 2. Grafik Nilai Serapan Air (\%) Paving Block Subtitusi Cangkang Sawit Berdasarkan 3 Perlakuan (P1. P2 dan P3).

Adapun ketegori penggunaan sesuai standar SNI adalah untuk Perlakuan 1 (P1) adalah peruntukannya untuk parkir, perlakuan 2 (P2) adalah untuk fasilitas pejalan kaki, sedangkan untuk perlakuam 3 (P3) dikhusukan penggunaannya untuk taman dan semacamnya. Sebagaimana pada SNI 01-069-1996.

\section{KESIMPULAN DAN SARAN}

\section{A. Kesimpulan}

1. Limbah cangkang sawit bisa digunakan sebagai material untuk subtitusi pada pembuatan paving block dan digunakan secara umum, memiliki kemamfaatan tersendiri pada proses pengunaan limbah.

2. Produk penelitian paving block yang memenuhi syarat dalam hal daya kuat tekan adalah produk dengan perlakuan P1 dan P2 , yakni komposisi perbandingan semen (S), Cangkang sawit (CS) dan Pasir (P) 1: 1.5: 4.5 (P1) dan 1 : 3(CS) : 3 (P2)

3. Nilai kuat tekan P1 dan P2 dalam standar SNI terkategori untuk penggunaan fasilitas parkir dan semacamnya.

4. Untuk nilai penyerapan air , semua perlakuan masuk dalam kategori standar 
SNI, namun yang paling memenuhi mutu tertinggi adalah P1 dengan kategori peruntukan untu lapangan parkir.

\section{B. Saran}

Perlu adanya perlakuan khusus pada cangkang sawit untuk menghilangkan lemak sebelum percampuran pra pembentukan paving blok agar menghindari terjadinya daya lekat yang kecil antara semen dan cangkang sawit.

\section{DAFTAR PUSTAKA}

Aditya, C, 2013. Pemanfaatn Limbah Pasir Kaca Sebagai Subtitusi Pasir Sungai Pada Paving Block. Teknik Sipil, UWM. Malang.

Badan Standarisasi Nasional. 1996. Standar Nasional Indonesia (SNI). SNI-03-06911996. Bata Beton. Jakarta: Dewan Standarisasi Indonesia.

Deden, D.T,. 2004. Pemanfaatan Limbah Tempurung Kelapa Sawit Untuk Pembuatan Paving Block. Teknik Sipil. UNS. Semarang.

Mustaqim, M.I,. 2011. Pengaruh Penambahan Abu Tempurung Kelapa Terhadap Kuat Tekan Paving Block. UPP. Riau.

Samiaji . 2010. Pembuatan Paving Block Dengan Menggunakan Limbah Abu Boiler PKS Gunung Bayu Sebagai Bahan Pengisi Dengan Perekat Alternative Limbah Fly Ash PLTU Sibolga. USU. Medan.

Sipayung. T,.2012. Ekonomi Agribisnis Minyak Sawit. IPB Press. Bogor. Vol 8. No 01-03.

Wariyatno. dan Haryanto,. 2013. Kuat Tekan Dan Kuat Tarik Belah Sebagai Nilai Estimasi Kekuatan Sisa Pada Beton Serat Kasa Aluminiumakibat Variasi Suhu, Jurnal Dinamika Rekayasa Vol. 9 No. 1 Feb. 2013. FT. Unsoed, Jawa Tengah. 